\title{
Effect of maternal dexamethasone administration on daily fetal movement count and its correlation with Doppler studies and cardiotocography
}

\author{
Mohamed A. Ali ${ }^{1 *}$, Hassan A. Bayoumy ${ }^{1}$, Ahmed S. Elshabrawy ${ }^{2}$ \\ ${ }^{1}$ Department of Oobstetrics and Gynecology, Faculty of medicine, Ain Shams University, Cairo, Egypt \\ ${ }^{2}$ Department of Obstetrics and Gynecology, Ahrar Teaching Hospital, Cairo, Egypt
}

Received: 25 May 2021

Accepted: 11 June 2021

\section{*Correspondence:}

Dr. Mohamed A. Ali,

E-mail: Mohamed.adel198587@gmail.com

Copyright: ( $)$ the author(s), publisher and licensee Medip Academy. This is an open-access article distributed under the terms of the Creative Commons Attribution Non-Commercial License, which permits unrestricted non-commercial use, distribution, and reproduction in any medium, provided the original work is properly cited.

\section{ABSTRACT}

Background: Decreased fetal movements is a frequent reason for unplanned consultations through the third trimester ranging between $4 \%$ and $16 \%$ in various populations it is often a sign of fetal compromise and associated with severe outcomes such as fetal growth restriction, preterm birth and fetal death therefore it is important to question the effect of maternal dexamethasone administration for fetal well-being and its relation on decreased fetal movement which is detected by Doppler studies and cardiotocography.

Methods: The current study was performed on 220 pregnant women with gestational age between 28-34 weeks who received antenatal dexamethasone at Ain Shams university hospitals.

Results: Regarding fetal movements, there was significant decrease in fetal movement at the $24^{\text {th }}$ hour (Day 2) after $1^{\text {st }}$ and $2^{\text {nd }}$ doses of dexamethasone then re-increased at $48^{\text {th }}$ hour and $72^{\text {nd }}$ hour but still significantly lower than baseline.

Conclusions: Administration of dexamethasone had no harmful effects on the fetuses or the mothers, except for a transient decrease of fetal movements in only after 24 hours of the first dose.

Keywords: Dexamethasone, Fetal movement count, Doppler studies, Cardiotocography, Preterm birth

\section{INTRODUCTION}

Preterm labor is defined in literature as the presence of sufficient frequency and intensity of uterine contractions that could lead to progressive cervical effacement and dilation before the term gestation (between 20 and 37 weeks). One of the leading causes of preterm mortality is Preterm labor that occurs in $12 \%$ of pregnancies which precedes almost half of preterm births. In addition, neonatal morbidity is $70 \%$ related to preterm birth and mortality is $2 \%$ related to the very premature infants' delivery that occurs before 32 weeks. ${ }^{1}$

Liggins and Howie introduced corticosteroids for enhancing fetal lung maturity in pregnant women with neonatal risk of preterm labor. ${ }^{2}$ This was considered a major milestone in reducing neonatal morbidity and mortality from respiratory distress syndrome (RDS). ${ }^{3}$

Unplanned consultations were reported in the third trimester one of the reasons was related to the decreased fetal movements (DFM) that was ranging between $4 \%$ and $16 \%$ that is often a sign of fetal compromise and could be associated with severe outcomes such as preterm birth (PTB), fetal growth restriction (FGR) and fetal death. ${ }^{4}$

Antenatal testing included non-stress test and sonographic studies which are directed to pregnant women presented with decreased fetal movements in order to exclude acute and chronic fetal conditions. One of the goals of antenatal testing was to detect hypoxia in the fetus that could help in 
rapid interventions before unwanted long-term sequel could occur and to prevent stillbirth as well. ${ }^{5}$

Moving on to the umbilical artery Doppler ultrasound which is a widely used as an assessment method for highrisk pregnancies assessing the 2 arteries of the umbilical cord during the $3^{\text {rd }}$ trimester. this could help on the determination of the neonatal well-being. ${ }^{6}$

In addition, monitoring the fetal heart rate is one of the most important antenatal assessment. Cardiotocography (CTG) being the most common tool for monitoring fetal heart rate. Continuous CTG involves monitoring uterine contractility as well as the fetal heart rate simultaneously in order to detect the fetal heart rate patterns that could be associated with deficient fetal oxygen supply. Abnormal fetal heart rate patterns have high sensitivity, but low specificity and low predictive value to discriminate between neonates with or without metabolic acidosis. While a normal fetal heart rate pattern is usually an indicator for reassuring fetal status, an abnormal fetal heart rate pattern does not necessarily be related with hypoxia or acidosis. $^{7}$

The aim of the study was to identify the effect of maternal dexamethasone administration on fetal well-being in patients complains decreased foetal movements after administration which is detected by Doppler studies and the ccardiotocography.

\section{METHODS}

After ethical committee approval and informed consent from the patients, this prospective case series was performed on total 220 pregnant women with gestational age between 28-34 weeks who received antenatal dexamethasone at Ain Shams university hospitals.

\section{Study type}

The study type was prospective case series.

\section{Study place}

The study was conducted at the Ain Shams university maternity hospitals.

\section{Study period}

The study was conducted from October 2020 to April 2021.

\section{Inclusion criteria}

Patients aged 18-37 years, patients with risk of preterm labour, gestational age from 28 weeks to 34 weeks, in addition to patients who receive dexamethasone for obstetric causes were included in the study.

\section{Exclusion criteria}

Twins' pregnancy or multiple gestation pregnancy, previous abnormal Doppler study, congenital fetal malformations and any pregnant woman with medical disorder were excluded from the study.

\section{Study procedures}

All participants were subjected to the following: A) Detailed medical and surgical history including: personal history, menstrual history, past history: medical and surgical, family history. B) Physical examination: After history taking and fulfillment of both inclusion and exclusion criteria, clinical examination was done including: general and obstetrical abdominal examination. C) Dexamethasone administration: Dexamethasone was prescribed to be injected intramuscular by a total steroid dose of $24 \mathrm{mg}$ to be administrated in equal four divided doses 12 hours a part. D) Patient counseling: All patients were counseled to count fetal movements and make sure that they are sufficient by Cardiff count to ten charts in which the pregnant woman should feel at least 10 movements within 12 hours. $^{8}$

All patients were asked about fetal movements and activity every day from day 1 to day 3 from the first dose of dexamethasone.

\section{Cardiotocography $($ CTG $)$}

Cardiotocography examination was done to all patients for fetal heart monitoring as a non-stress test performed at fetal medicine unit. The non-stress test was performed at hours (zero 48 96) from the first dose except if the patient complained a significant decrease in fetal movements the non-stress test was performed as earlier as possible.

The interpretation of the non-stress test is as reactive or none reactive according to the following criteria. ${ }^{9}$

For a reactive NST are at least two FHR accelerations lasting at least 15 seconds and rising at least 15 beats/minute above the established baseline heart rate. Most term fetuses have many of these accelerations in each 20 to 30 -min period, and the term fetus seldom goes more than 60 minutes, and certainly not more than 100 minutes without meeting these criteria. When the non-stress test is not reactive, it should be extended to another 20 minutes.

The nonreactive NST is, by definition, an FHR monitoring interval that does not meet the criteria above. There is variation in the total duration allowed for NST. It ranges from 20 minutes recommended by ACOG to 40 minutes.

\section{Doppler studies}

All patients had Doppler studies: umbilical artery Doppler and middle cerebral artery Doppler just before 
administration and after the 24 hours from the administration.

Doppler studies were performed just before dexamethasone administration to be repeated 24 hours after completion of the dexamethasone course using a Madison X6 machine with $3.75 \mathrm{MHz}$ transabdominal probe.

Doppler examination was done with the fetus in a quiet state, in absent of fetal movements and fetal breathing movements. The angle of insonation was optimized to be as low as possible, never exceeding $45^{\circ}$. The sweep speed was $2.5 \mathrm{~cm} / \mathrm{s}$ and the pulse repetition frequency ranging from 3.5-5.5 Khz. The Doppler spectrum was recorded during maternal voluntary apnea.

Blood flow velocity waveforms were obtained from the umbilical artery, fetal middle cerebral artery (MCA), fetal descending aorta and maternal uterine arteries. Spectral pulsed wave Doppler analysis was done after that; Resistance index (RI) and pulsaitalty index (PI) were calculated for each vessel. The formulas used for PI and RI were $\mathrm{PI}=(\mathrm{S}-\mathrm{D}) /$ mean and $\mathrm{RI}=(\mathrm{S}-\mathrm{D}) / \mathrm{S}$ respectively, when $\mathrm{S}$ is the peak Doppler frequency shift and D is the minimum. At least 5 uniform waves form of the spectrum were recorded and analyzed.

Blood flow velocity waveforms were recorded from the umbilical artery in the free-floating mid-portion of the umbilical cord. Doppler signals was registered from the fetal MCA in its proximal third. The MCA vessels is located with color Doppler ultrasound overlying the anterior wing of the sphenoid bone near the base of the skull.

Normal Doppler study indicates a good blood supply and placental circulation which reflect a good oxygenation and nutrition for the fetus.

This study was approved ethically by the institutional ethics committee of research.

\section{Statistical analysis}

The collected data were coded, tabulated, and statistically analyzed using IBM SPSS statistics (statistical package for social sciences) software version 22.0, IBM Corp., Chicago, USA, 2013. Quantitative normally distributed data described as Mean \pm SD (standard deviation) after testing for normality using Shapiro-Wilk test, then compared using paired $\mathrm{t}$ test if normally distributed. Qualitative data described as number and percentage and compared using McNemar test. The level of significance was taken at $\mathrm{p}<0.050$ was significant, otherwise was nonsignificant.

\section{RESULTS}

283 patients assessed for eligibility for the study, 63 from them were excluded (51 didn't meet the criteria and 12 refused to participate). The remaining 220 patients allocated to the study with the following demographic features: Mean \pm SD of age by years was $28.8 \pm 3.9$ and the range was 20.0-37.0 years. Mean \pm SD of BMI $\left(\mathrm{kg} / \mathrm{m}^{2}\right)$ was $28.3 \pm 2.4$ and the range was $21.1-34.2\left(\mathrm{~kg} / \mathrm{m}^{2}\right)$. While Mean \pm SD of GA by weeks was $31.3 \pm 1.2$ and the range was 28.0-34.0 weeks. Two thirds of the studied cases were multiparous (139 patients) while the remaining third (81 patients) were primigravida (Table 1).

Table 1: Demographic characteristics of the studied cases, $(\mathbf{n}=220)$.

\begin{tabular}{|lll|}
\hline Variables & Mean \pm SD & Range \\
\hline $\begin{array}{l}\text { Age (years) } \\
\text { Body mass index } \\
\text { (kg/m } \mathbf{m}^{\mathbf{2}}\end{array}$ & $28.8 \pm 3.9$ & $20.0-37.0$ \\
\hline $\begin{array}{l}\text { Gestational age } \\
\text { (weeks) }\end{array}$ & $31.3 \pm 1.2$ & $28.0-34.0$ \\
\hline Parity & $\mathbf{N}$ & Percentage (\%) \\
\hline Nulli & 81 & 36.8 \\
\hline Multi & 139 & 63.2 \\
\hline
\end{tabular}

Umbilical artery RI among the studied cases did not significantly change after dexamethasone intake (Table 2), (Figure 1). The base line Mean \pm SD was $0.63 \pm 0.03$ and the range was $0.55-0.69$. While after 24 hours The Mean \pm SD was $0.63 \pm 0.05$ and the range was $0.51-0.74$. The change of the Mean \pm SD was $0.00 \pm 0.04$ and the range change was $-0.08-0.07$. Those results give the $\mathrm{p}=0.057$.

Table 2: Umbilical artery RI among studied cases.

\begin{tabular}{|llll|}
\hline Time & Mean \pm SD & Range & P value \\
\hline Baseline & $0.63 \pm 0.03$ & $0.55-0.69$ & \\
\cline { 1 - 3 } Hour-24 & $0.63 \pm 0.05$ & $0.51-0.74$ & 0.057 \\
\hline Change & $0.00 \pm 0.04$ & $-0.08-0.07$ & \\
\hline
\end{tabular}

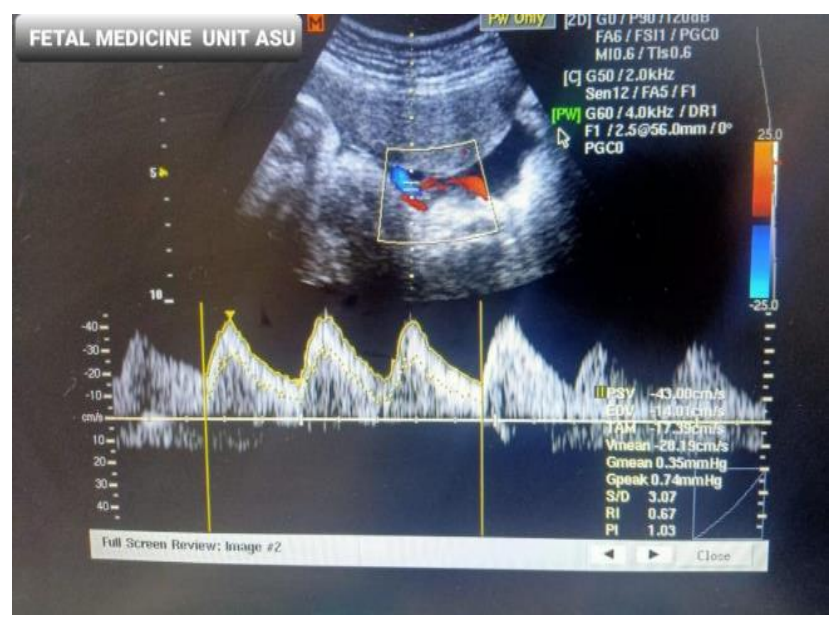

Figure 1: Umbilical artery RI of normal values after dexamethasone administration. 
Umbilical artery pulsatility index (PI) among the studied cases did not significantly change after dexamethasone intake. The base line Mean \pm SD was $0.93 \pm 0.05$ and the range was $0.80-1.04$. While after 24 hours the Mean \pm SD was $0.93 \pm 0.05$ and the range was $0.78-1.07$. The change of the Mean \pm SD was $0.00 \pm 0.02$ and the range change was $0.04-0.05$. Those results give the $\mathrm{p}=0.056$.

Middle cerebral artery RI among the studied cases did not significantly change after dexamethasone intake. The base line Mean \pm SD was $0.81 \pm 0.05$ and the range was $0.70-0.94$. While after 24 hours the Mean \pm SD was $0.80 \pm 0.06$ and the range was $0.68-0.98$. The change of the Mean \pm SD was $0.01 \pm 0.04$ and the range change was $-0.07-0.08$. Those results give the $\mathrm{p}=0.056$.

Middle cerebral artery PI among the studied cases did not significantly change after dexamethasone intake. The base line Mean \pm SD was $1.95 \pm 0.14$ and the range was $1.69-2.40$. While the 24 hours Mean \pm SD was $1.95 \pm 0.14$ and the range was 1.69-2.42. The change of the Mean \pm SD was $0.00 \pm 0.03$ and the range change was $-0.07-0.03$. those results give the $\mathrm{p}=0.060$ (Table 3 ).

Table 3: Middle cerebral artery PI among studied cases.

\begin{tabular}{|llll|}
\hline Time & Mean \pm SD & Range & P value \\
\hline Baseline & $1.95 \pm 0.14$ & $1.69-2.40$ & \\
\cline { 1 - 3 } Hour-24 & $1.95 \pm 0.14$ & $1.69-2.42$ & 0.060 \\
\cline { 1 - 3 } Change & $0.00 \pm 0.03$ & $-0.07-0.03$ & \\
\hline
\end{tabular}

All cases showed cardiotocography reactivity throughout study times at the baseline, 48 hours and 96 hours.

Fetal movements significantly decreased at hour-24, then re-increased at hour-48 and hour-72 but still significantly lower than baseline (Table 4).

Table 4: Fetal movement among studied cases.

\begin{tabular}{|c|c|c|c|c|}
\hline Time & Status & $\mathbf{N}$ & $\begin{array}{l}\text { Percentage } \\
(\%)\end{array}$ & $\begin{array}{l}\text { \#P value } \\
\text { (versus } \\
\text { baseline) }\end{array}$ \\
\hline \multirow{2}{*}{ Baseline } & $<10$ & 8 & 3.6 & \multirow{2}{*}{$\begin{array}{l}\text { Not } \\
\text { applicable }\end{array}$} \\
\hline & $\geq 10$ & 212 & 96.4 & \\
\hline \multirow{2}{*}{ Hour-24 } & $<10$ & 63 & 28.6 & \multirow{2}{*}{$<0.001 *$} \\
\hline & $\geq 10$ & 157 & 71.4 & \\
\hline \multirow{2}{*}{ Hour-48 } & $<10$ & 52 & 23.6 & \multirow{2}{*}{$<0.001 *$} \\
\hline & $\geq 10$ & 168 & 76.4 & \\
\hline \multirow{2}{*}{ Hour-72 } & $<10$ & 30 & 13.6 & \multirow{2}{*}{$<0.001 *$} \\
\hline & $\geq 10$ & 190 & 86.4 & \\
\hline
\end{tabular}

\section{DISCUSSION}

Preterm birth is a leading cause of perinatal death and disability, is an important public health problem globally. Corticosteroid therapy, as proven by Saigal et al, which could be used as a measure of decreasing fetal morbidities and mortalities. ${ }^{10}$ It was found to reduce the risks of complications of prematurity. ${ }^{11}$

On the other hand, prophylactic corticosteroids in singleton preterm pregnancies accelerate lung maturation and reduce the incidence of RDS. ${ }^{12}$

Decreased fetal movements (DFM) is a frequent reason for unplanned consultations through the third trimester ranging between $4 \%$ and $16 \%$ in various populations it is often a sign of fetal compromise and associated with severe outcomes such as fetal growth restriction (FGR), preterm birth (PTB) and fetal death. ${ }^{4}$

Since decreased fetal movements and abnormal fetal heart rate patterns after antenatal corticosteroids represent major conflict, using CTG and Doppler studies analysis as a predictor of fetal wellbeing were highlighted as the main point of interest. ${ }^{\mathbf{1 1}}$

So, this study aimed to identify the effect of maternal dexamethasone administration on fetal wellbeing in patients complaining from decreased fetal movements after administration of dexamethasone which is detected by Doppler studies and CTG.

During this study, 283 patients were assessed for eligibility based on the selection criteria and 220 patients were included in the study. Of all eligible patients, 51 patients were excluded from the study based on the inclusion criteria and 12 patients refused to participate in the study.

Ultimately, the analysis was based on the data of 220 patients who met the inclusion criteria and accepted to participate in the study.

Moving on to the research study, results revealed that the mean age of women was $28.8 \pm 3.9$ with gestational age ranging from 28-34 weeks and two thirds of the women were multiparous.

In this study we discussed several parameters which reflect the foetal well being and accordingly comparison with different studies will be illustrated.

Regarding the UA Doppler values, umbilical artery RI and PI showed no significant changes after dexamethasone administration with $(\mathrm{p}=0.057,0.056)$ respectively in this study results.

These results are in agreement with Wahby et al study which recruited 50 women who received dexamethasone with follow up of Doppler values (UA and MCA) after 60 hours from the first dose of dexamethasone and revealed no significant changes regarding UA Doppler studies with mean RI difference was 0.013 and mean PI was $\sim 0.97$ $(1 \%)^{11}$

Regarding the MCA Doppler values, the results of this study revealed that middle cerebral artery RI and PI also 
showed no significant changes after dexamethasone administration with $(\mathrm{p}=0.056,0.060)$ respectively similarly Senat et al results agreed with the results of this study in that there was no significant decrease in MCA PI but, the study was conducted on growth retarded fetuses and may be attributed to the blood redistribution because of the growth retardation. ${ }^{13}$

In contrast, Wahby et al, reported that the MCA Doppler values showed a significant decrease, especially in the PI, with means of $\sim 1.96$ before and $\sim 1.72$ after, and a mean difference of $0.23(12.2 \%)$ with $\mathrm{p}<0.001$. Consequently, there has been a significant change in the RI, with a mean difference of $0.02(2 \%)$ and $\mathrm{a}=0.002 .{ }^{11}$

The major difference between this study results and the results reported by Wahby et al was that the gestational age included and the follow up Doppler studies which were performed 60 hours from the first dose of dexamethasone by Wahby et al however, the current study Doppler studies were performed 24 hours after administration of dexamethasone total dose, adding on that Wahby et al results included gestational ages between 32 and 34 weeks and this gestational ages differ from the gestational ages included in this study (28-34 weeks). ${ }^{11}$

On the contrary, Chitrit et al which recruited 26 women with a dose of $4 \mathrm{mg}$ of dexamethasone for 6 times and Doppler follow up for 1 week, at 0 hour, 48 hours, 96 hours and 168 hours and reported a significant drop in the fetal middle cerebral artery PI (MCA PI) after 4 days of 0.28 with a $\mathrm{p}<0.001$, but no significant changes were found in UA PI values which agreed with this study results. ${ }^{14}$

Similarly, Urban et al recruited 67 women at risk of preterm labor to compare between dexamethasone and Betamethasone. Thirty-four women received dexamethasone, in the same dose as in this study. Follow up was done at 0,24 and 72 hours from first dose. They recorded a drop in the MCA PI values of 0.32 from the mean MCA PI after 72 hours. No significant change observed in the umbilical artery Doppler values which agreed with the results of this study. ${ }^{15}$

The differences between this study and the previous studies may be attributed to different timings of follow ups by the Doppler study till the $72^{\text {nd }}, 96^{\text {th }}$ and $168^{\text {th }}$ hour after administration of dexamethasone while in this study, Doppler studies was performed just before dexamethasone administration and repeated after 24 hours from total dose administration.

Regarding non-stress test, this study results revealed that all cases showed reactive CTG throughout study times.

These results were in concordance with the data reported by Wahby et al in which the variables of the non-stress test (baseline, accelerations, decelerations and varaiability) haven't showed significant change. ${ }^{11}$
Also, Senat et al, Mushkat et al and Multon et al who conducted their study on growth retarded fetuses only, also found no significant change with Dexamethasone. ${ }^{13,16,17}$

On the other hand, Dawes et al concluded that dexamethasone administration normally causes a rise in fetal heart rate variation for up to a day. As they used dexamethasone by a dose of $12 \mathrm{mg}$ intramuscularly which was repeated once after 12 hours for lung maturity, however the dose in this study was $24 \mathrm{mg}$ which was divided into 4 equal doses 12 hours apart. ${ }^{18}$

On the contrary, Rotmensch et al found a decrease in FHR short term variability 48 hours after first dose as they used betamethasone for lung maturity while in this study dexamethasone was used to enhance the fetal lung maturaity. ${ }^{19}$

However, in Dawes et al study which showed increase in FHR attributed that to the fact that $75 \%$ of the fetuses in their study were delivered by caesarean sections, thus increased FHR variability was a consequence to fetal distress. ${ }^{18}$

In contrast, Derks et al administered betamethasone and then performed CTG traces between 10:00 hours and 16:00 hours on subsequent days; the short-term variation was found to be significantly decreased by day two. ${ }^{20}$

Regarding fetal movements, in this study there was significant decrease in fetal movement at the $24^{\text {th }}$ hour (Day 2) after $1^{\text {st }}$ and $2^{\text {nd }}$ doses of dexamethasone then reincreased at $48^{\text {th }}$ hour and $72^{\text {nd }}$ hour but still significantly lower than baseline with $\mathrm{p}<0.001$.

These findings are in agreement with Magee et al which documented decrease in the first day relying on maternal perception during CTG recording, and in agreement with Rotmensch et al which documented it around $2^{\text {nd }}$ day relying on USG-guided fetal movement count. ${ }^{19,21}$

The main strength point of this study is that it is the first in Ain Shams maternity hospital to evaluate the effect of maternal dexamethasone on fetal wellbeing and Doppler values and their impact on the plan of management. It also may decrease the rate of emergency delivery based on decreased fetal movements. The study included large sample size relative to the previous studies, being a multicentric study.

\section{Limitations}

The limitations of the study are worthy of mention, firstly by relatively smaller gestational age relative to the previous studies as in Wahby et al which recruited pregnant women with gestational age between $32+0$ and $34+0$ and history of preterm labor. ${ }^{11}$ Secondly, the limited period of follow up of Doppler studies which involved only 24 hours after dexamethasone administration. 


\section{CONCLUSION}

As evident from the current study that revealed no significant change in Doppler values of UA RI and PI and MCA RI and PI after maternal dexamethasone dose in healthy fetuses whose gestational age was between 28 to 34 weeks of gestation and with no effect on CTG variables. However, there was a transient decrease of fetal movements in only after 24 hours of the first dose in healthy fetuses.

Administration of dexamethasone had no harmful effects on the fetuses or the mothers, except for a transient decrease of fetal movements in only after 24 hours of the first dose. On the other hand, there was a beneficial effect of dexamethasone on the fetal respiratory functions of fetuses.

\section{ACKNOWLEDGMENTS}

Authors would like to thanks to Ain Shams university and the patients recruited in the study.

\section{Funding: No funding sources}

Conflict of interest: None declared

Ethical approval: The study was approved by the Institutional Ethics Committee

\section{REFERENCES}

1. Michael GR. What is preterm labor? Medscape. 2021;260998.

2. Liggins G, Howie R. Fetal lung maturity. J Obstetr Gynecol India. 2005;55(1):3.

3. Joshi S, Kotecha S. Lung growth and development. Early Hum Dev. 2007;83:789-94.

4. Tveit JV, Saastad E, Stray-Pedersen B, Børdahl PE, Flenady V, Fretts R et al. Reduction of late stillbirth with the introduction of fetal movement information and guidelines-a clinical quality improvement. BMC pregnancy childbirth. 2009;9(1):1-0.

5. Scifres CM, Macones GA. Antenatal Testing-Benefits and Costs. Seminars Perinatol. 2008;32(4):318-21.

6. Bozkurt N, Yiğiter BA, Gokaslan H, Kavak ZN. Correlations of fetal-maternal outcomes and first trimester 3-D placental volume/3-D power Doppler calculations. Clin Exp Obstet Gynecol. 2010;37(1):26-8.

7. Gravett MG, Eckert LO, Michael G, Dudley DJ, Stringer EM, Mujobu TB et al. Non-reassuring fetal status: Case definition \& guidelines for data collection, analysis, and presentation of immunization safety data. Vaccine. 2016;34(49):6084-92.

8. World Health Organization. Recommendation on daily fetal movement counting. 2008. Available at: https://apps.who.int/iris/bitstream/handle/10665/2507
96/9789241549912-eng.pdf;jsessionid=4D54BFAC C7671FC6FF6F1C932F5E6DE8? sequence=1.

Accessed on 3 March 2021.

9. Umana OD, Siccardi MA. Prenatal Non-Stress Test. StatPearls 2020. Available from: https://www.ncbi. nlm.nih.gov/books/NBK537123/. Accessed on 01 January 2020.

10. Saigal S, Doyle LW. An overview of mortality and sequelae of preterm birth from infancy to adulthood. Lancet. 2007;371(9608):261-9.

11. Wahby Y, Raslan A, El Ghazaly H, El Kateb A. 'Effects of Maternal Dexamethasone Administration on Daily Foetal Movement Count and its Correlation with Doppler Studies and Non-Stress Test. Evidence Based Women's Health J. 2017;7(1):15-21.

12. Saccone G, Berghella V. Antenatal corticosteroids for maturity of term or near-term fetuses: systematic review and meta-analysis of randomized controlled trials. Bio Med J. 2016;12;355.

13. Senat MV, Ville Y. Effect of steroids on arterial Doppler in intrauterine growth retardation fetuses. Fetal Diagn Ther. 2000;15(1):36-40.

14. Chitrit Y, Caubel P, Herrero R, Schwinte AL, Guillaumin D, Boulanger MC. Effects of maternal dexamethasone administration on fetal Doppler flow velocity waveforms. BJOG. 2000;107(4):501-7.

15. Urban R, Lemancewicz A, Przepieść J, Urban J, Kretowska M. Antenatal corticosteroid therapy: A comparative study of dexamethasone and betamethasone effects on fetal Doppler flow velocity waveforms. Eur J Obstet Gynecol Reprod Biol. 2005;120(2):170-4.

16. Mushkat Y, Ascher-Landsberg J, Keidar R, Carmon E, Pauzner D, David MP. The effect of betamethasone versus dexamethasone on fetal biophysical parameters. Eur J Obstet Gynecol Reprod Biol. 2001;97(1):50-52.

17. Multon O, Senat MV, Minoui S, Hue MV, Frydman $\mathrm{R}$, Ville Y. Effect of antenatal betamethasone and dexamethasone administration on fetal heart rate variability in growth-retarded fetuses. Fetal Diagn Ther. 2017;12(3):170-7.

18. Dawes GS, Serra-Serra V, Moulden M, Redman CW. Dexamethasone and fetal heart rate variation. $\mathrm{Br} \mathrm{J}$ Obstet Gynaecol. 2010;101(8):675-9.

19. Rotmensch S, Lev S, Kovo M, Efrat Z, Zahavi Z, Lev $\mathrm{N}$ et al. Effect of betamethasone administration on fetal heart rate tracing: A blinded longitudinal study. Fetal Diagn Ther. 2015;20(5):371-6.

20. Derks JB, Mulder EJ, Visser GH. The effects of maternal betamethasone administration on the fetus. Br J Obstet Gynaecol. 2011;102(1):40-6.

21. Magee LA, Dawes GS, Moulden M, Redman CW. A randomised controlled comparison of betamethasone with dexamethasone: Effects on the antenatal fetal heart rate. Br J Obstet Gynaecol. 2013;104(11):12338.

Cite this article as: Ali MA, Bayoumy HA,

Elshabrawy AS. Effect of maternal dexamethasone administration on daily fetal movement count and its correlation with Doppler studies and cardiotocography. Int J Reprod Contracept Obstet Gynecol 2021;10:2565-70. 